attending any extension of a student's career, especially for the majority whose work is less absorbing than research and where compensations are necessary. Specialization, or differentiation, should not come before the third year, and even then should not involve a student being committed to one field for the rest of his life. He believes that we need more training in administration for a limited number of people, who would in due course take their place with those who have studied life from a different aspect. Then we should retain, and possibly extend, a completely free atmosphere for those students who take naturally to research. We also need a better administrative attitude to research, and also technical high-schools and extended facilities in the ordinary technical schools.

Prof. H. V. A. Briscoe confined himself to the question of producing men destined for teaching positions in pure and applied science and in the industries using applied science. He stressed the importance in recruitment of selection and of widening the field of choice; we must look critically and constructively at this question of extended recruitment and make a scientific career attract more of the really good men who at present go into other fields. Then he stressed the importance of excellence in the teaching staff with reference to imparting selected principles and facts in science so as to inculcate and develop intelloctual integrity and to display the cultural aspects of science, as well as to the provision of opportunities for special development. Curricula are overloaded, and we must remember that the task is education, not teaching. Lastly, there is the question of assessment and guidance in the valuation of the graduate, so that he does what is best in his own interest and in the interests of the community. Here full co-operation of the employer is essential. With regard to the desirability of having first-class men for production, he believes that the choice between research and production should be left open and that we should aim at turning out keen, properly equipped scientific workers, whose careers would be determined by their aptitudes and opportunities.

Dr. R. V. Southwell, stressing the importance of a real partnership with industry, suggested that we may find that the best arrangement is not one in which three years at a university are followed by two years in industry, but one in which the last of the five years sees a man returning to his university. A man who enters industry should not have finished with his university, and we might well keep a more open mind on the order in which the years are spent between industry and the university.

Mr. J. W. Sawtell emphasized the importance of good management; he thinks that we should impress on the universities the need for men with a scientific education who can manage and handle other poople, and appreciate the importance and dignity of management as a profession. Mr. L. P. Combes pointed out that regard must be had to the question of national service and its incidence on the age of recruitment. Mr. D. A. Bell thinks that one reason why graduates tend to enter industry only in research departments is that management has not been regarded as a worthy or scientific profession. In written subsequent contributions, Mr. W. S. Flight referred to the economic difficulties of a long period of training and a possible solution through the State bursary scheme, and Mr. M. I. Freeman urged that some training in the principles of industrial administration and organization should be given by the university rather than by industry.

Dr. A. J. F. Welch referred to the importance of vacation work and of having on academic staffs those with first-hand acquaintance with industrial conditions, while Dr. F. M. Potter, urging the value of a sound fundamental knowledge and elementary back. ground of several subsidiary sciences, suggested that students would do well to avoid the tendency to live with men in the same year who are studying the same branch of seience.

\section{MODE OF ACTION OF PENICILLIN}

$\mathbf{N}$ an article on penicillin treatment in Nature $(677$, Nov. 25, 1944) reference was made to the work of Lieut.-Colonel J. W. Bigger (Lancet, 497, Oct. 14, 1944), who concluded that penicillin actually kills Staphylococcus pyogenes. He suggested that it kills them at the time of division and has no effect upon individual cocci which are not dividing. These, therefore, persist in broth cultures, which penicillin frequently fails to sterilize, and are the explanation of that failure. Bigger proposed to give penicillin intermittently, in the hope that these 'persisters' would begin dividing in the intervals of the penicillin doses and so would be killed by the next dose. Bigger refers to the work of C. D. Gardner (Nature, 146, 837 ; 1940), who found that, in weak concentrations of penicillin, cocci swelled to three times their normal size without division, and bacilli showed similar changes.

E. W. Todd (Lancet, 74, Jan. 20, 1945) also refers to this and other work in his report on his experiments on the bacteriolytic action of penicillin. Working with Pneumococcus Types I, II and III and with Streptococcus viridans, hæmolytic streptococci, staphylococci and Clostridium welchii, he found that all the strains of these organisms which he used were lysed by penicillin, but that such organisms as Bact. coli and Pseudomonas pyocyanea, which resist penicillin, were not lysed by it. But penicillin, he concluded, can kill organisms without lysis. When lysis occurs, its rate depends on the actual or potential rate of multiplication of the organisms. Their multiplication, as G. L. Hobby, K. Meyer and E. Chaffee (Proc. Soc. Expt. Biol., N.Y., 50, 281; 1942) also found, is essential for the action of penicillin. "It would appear that bacteriostasis, bactericidal action and bacteriolysis may be different stages of a single process proceeding in that order." The most rapid lysis occurs with organisms at the maximal rate of multiplication. This may be the real reason why penicillin is so effective, that is, because young actively multiplying cultures are more susceptible to bacteriolysis, so that organisms in the phase which enables them most readily to invade the human body are also then most susceptible to lysis.

These conclusions may be compared with those of Prof. L. P. Garrod (Brit. Med. J., 108, Jan 27, 1945), who agrees that penicillin actually kills susceptible bacteria. $\mathrm{He}_{\theta}$ quotes the further opinion of $\mathrm{L}$. A. Rautz and W. M. M. Kirby (J. Immunol., 48, 335 ; $1944)$ that penicillin is actually bactericidal. Garrod gives, however, only qualified support to Bigger's hypothesis that penicillin is bactericidal only to organisms when they are about to divide, which was, he says, also put forward by G. L. Hobby and M. H. Dawson (Proc. Soc. Expt. Biol., N.Y., 56, 178 ; 1944) and by C. P. Miller and A. Z. Foster (ibid., 56, 205). 
Against this hypothesis, Garrod maintains, are (1) his experiments on the effects of temperature; like other disinfectants, penicillin is more active at higher temperatures, but is even more active at $42^{\circ} \mathrm{C}$., when bacterial growth ceases, than at $37^{\circ} \mathrm{C}$.; incidentally, Garrod finds that its action is impaired by increase of the acidity between $p \mathrm{H} 7 \cdot 0$ and $5 \cdot 0$ (2) the fact that bacteria from both old and very young cultures are almost uniformly susceptible. Garrod therefore thinks that there is no conclusive evidence in support of Bigger's proposal to give penicillin intermittently, and claims that clinical experience supports his view. Penicillin treatment fails because the organisms are inaccessible inside necrotic areas or in undetected abscesses.

Further important conclusions drawn by Garrod are that nothing is to be gained by using higher concentrations of penicillin (cf. Sir A. Fleming, Lancet, 621, Nov. 11, 1944; see also Nature, 155, 341, March 17, 1945), especially in local treatment. The idea that higher doses will be more effective does not apply to penicillin. The reverse is truer. A concentration of 1 unit per c.c. is not only just as effective as one of 1,000 units, but is often more effective. The only good reason for using stronger solutions in local treatment is to ensure that the concentration does not fall below the minimum fully effective level of about $0 \cdot 1$ unit per c.c. Garrod further emphasizes the importance of the purity of the penicillin which is being used experimentally. He found that all commercial penicillins tested were less active in higher than in low concentrations. Presum. ably impurities were responsible for this, and they cause serious obstacles to the study of the action of penicillin. It will be necessary to find out whether penicillin is a single substance of unvarying composition and uniform action.

Discussing these results in a valuable leading article, the British Medical Journal (123, Jan. 27, 1945) directs attention to the enormous variation in the susceptibility of various bacteria to penicillin. Some species classed as totally resistant are affected by higher concentrations of penicillin; for example, the typhoid bacillus and the salmonellas. H. F. Helmholz and C. Sung (Amer. J. Dis. Children, 68, 236 ; 1944) have found that some resistant bacteria in the urine are affected by high concentrations, for example, Proteus and some strains of B. coli. Only Bact. aerogenes and Pseudomonas pyocyanea remained unaffected. The treatment of some infections of the urinary tract with penicillin might thus be effective. E. W. Todd, G. S. Turner and L. G. W. Drew (Brit. Med.J., 111, Jan. 27, 1945) have found that Staphylococcus strain Oxford $H$. can be trained by growth in increasing quantities of penicillin to become 3,000 times more resistant to penicillin than it originally was. Similar results were obtained with another strain of Staphylococcus. Unlike other organisms which become 'drug-fast', however, Staphylococcus lost this property rapidly in media not containing penicillin. The authors refer to work which showed, on the other hand, that pneumococcus type III, made resistant to penicillin, either by culture in media containing penicillin (G. Rake et al., J. Immunol., 48, $271 ; 1944$ ) or by passage through mice treated with penicillin (L. H. Schmidt and C. L. Sesler, Proc. Soc. Expt. Biol., N.Y., 52, $353 ; 1943)$, retained its resistance. The nature of these phenomena of resistance requires further investigation. Although some organisms can produce a penicillinase which destroys penicillin (see, for example, the penicillinase produced by $B$. subtilis reported by E. S. Duthie, Brit. $J$. Expt. Path., 25, 96 ; 1944), resistance to penicillin apparently does not always depend on the production by the resistant organism of penicillinase. W. M. Kirby (Science, 452, June 2, 1944) has extracted a substance which is not penicillinase from Staphylococcus resistant to penicillin.

G. LAPAGE.

\section{INDIAN FOREST YIELD TABLES}

E. VER since the Forest Research Institute came into being at Dehra Dun (1907), the Sylvicultural Branch set out to obtain data for the preparation of volume and yield tables for some of the more important timbers such as teak, sal, and deodar, to mention but three of the best known throughout India. Selected sample plots of varying type and age had been previously formed by the forest officer in different parts of India, and more or less periodically measured and records kept. But for the most part the work was spasmodic and a proportion at least of the data obtained of doubtful usefulness.

As a result of the work inaugurated, attempts were made to prepare yield tables, among others, for the sal (Shorea robusta); such a table was prepared by Smythies and Howard and published in 1923. It was based on the measurements of some fifty-two plots of sal, chiefly in the United Provinces, with a few in Bengal and the Central Provinces. The sal has a wide distribution from the foothills and neigh. bouring border in the plains in the United Provinces as far west as the Jumna River, eastwards along this line through Nepal and Bengal Duars into Assam as far as Tezpur, its eastern boundary. To the south it is found in the eastern part of the Central Provinces and in Chota Nagpur, south-western Bengal, Orissa Province and Orissa Feudatory States to Ganjam in the Madras Provinces. It thus is equally at home in a dry hot as well as in a damp hot climate, and grows on a variety of soil conditions. Since the above tables were published, many more data have been collected, and this information has been collated in Indian Forest Records (Sylviculture) New Series, "Yield and Stand Tables for Sal (Shorea robusta) High Forest" (4.A., No. 4, Model Press, Delhi, 1943) by M. L. Griffith, sylviculturist, and Bakhshi Sant Ram. The present tables are based on 542 measurements from 225 sample plots in twenty-five forest divisions of five provinces. Sample plot selection, upkeep and measurements in the different provinces are now greatly facilitated by the existence in the provinces of provincial sylvicultural research officers whose investigations and results are available to the Central Research Institute. That this departure is of the highest value is evidenced by the authors' remark, "The tables now produced are admittedly not completely satisfactory on account of the abnormality of some of the basic data. The main difficulties arose through inconsistent thinning procedure. These have been described in more detail together with the methods attempted to overcome them."

Just as the progress in ordered management of a forest department is indicated by the number of the forests which have been placed under working plans, including the type of plan in force, so the degree to which sylvicultural work has advanced is evidenced by the possibility of being able to prepare suitable yield and stand tables for use in the forests under management. 